\title{
Dietary Diversity and Associated Factors among HIV Positive Adult Patients Attending Public Health Facilities in Motta Town, East Gojjam Zone, Northwest Ethiopia, 2017
}

\author{
Addisu Tesfaw, ${ }^{1}$ Dube Jara, ${ }^{2}$ and Habtamu Temesgen ${ }^{3}{ }^{3}$ \\ ${ }^{1}$ Gendewoyin Health center, Gonchasiso Enese Woreda, North West Ethiopia, Ethiopia \\ ${ }^{2}$ Department of Public Health, College of Health Sciences, Debre Markos University, Debre Markos, Ethiopia \\ ${ }^{3}$ Department of Human Nutrition and Food Science, College of Health Sciences, Debre Markos University, Debre Markos, Ethiopia \\ Correspondence should be addressed to Habtamu Temesgen; habtamutem@gmail.com
}

Received 10 July 2018; Revised 20 November 2018; Accepted 6 December 2018; Published 13 December 2018

Academic Editor: Giuseppe La Torre

Copyright (C) 2018 Addisu Tesfaw et al. This is an open access article distributed under the Creative Commons Attribution License, which permits unrestricted use, distribution, and reproduction in any medium, provided the original work is properly cited.

\begin{abstract}
Introduction. Dietary diversity is defined as the amount of different food groups or foods that are consumed over a specific reference time. The human immune deficiency virus problem remains one of the main public health challenges, especially in low and middle income countries. Nutrition has been linked to both the transmission of human immune deficiency virus and poor outcomes related to human immune deficiency virus. Objective. To assess dietary diversity and associated factors among human immune deficiency virus positive adult patients in Motta administrative town, Northwest Ethiopia, 2017. Methods. A facility based crosssectional study design was conducted on 410 study participants selected using a stratified sampling technique with proportional allocation. The data were collected using semi-structured and pretested questionnaire. Data were entered into Epi-Data version 3.1 and analysis was performed using SPSS version 20. Descriptive statistics were used to describe the number and percentage of the study variables. The bivariate and multivariable logistic regression analyses were done to identify the independent factors associated with dietary diversity among adult human immune virus (HIV) positive patients. Result. A total of 410 study participants were included in the analysis. Of the total, 121 (29.5\%) of adult HIV positive respondents consumed diversified diet with the mean dietary diversity score of 3.2 ( $\mathrm{SD} \pm 1.88$ ). The predominant food item consumed during the study periods was starchy staples $(96.1 \%)$ and legumes (81.7\%). Having means of communication cell phone (mobile phone) [( $\mathrm{AOR}=2.13(1.16,3.60)]$, media exposure status in the household $[(\mathrm{AOR}=1.95(1.22,3.11)]$ and nutrition counselling [ $(\mathrm{AOR}=2.17(1.09,4.67)]$ were significant factors associated with dietary diversified feeding at $95 \%$ CI. Conclusion. The study revealed that low dietary diversity score was significant nutritional problem among HIV positive adults in Motta town health facilities. Having mobile cell phone, media exposure status and nutritional counseling were significantly associated with dietary diversity score. Therefore efforts should be strengthened to improve the counseling service at each health institution and encourage the patients to use media for the source of information.
\end{abstract}

\section{Background}

Dietary diversity is a quantitative number of food groups which is used extensively as a method of ascertaining variety and nutrient adequacy of diets. It is the number of different food groups consumed over a given reference period. Diversified diets that include a variety of foods from different food groups (vegetables, fruits, grains, and animal source foods) provide a balance of nutrients that promote healthy growth and development. It is indeed strongly associated with nutrient adequacy [1]. Increasing the variety of foods across and within food groups is recommended in most dietary guidelines. This explained that there is no any single food which contains all the required nutrients for optimal health [2].

Undiversified food and malnutrition are public health concerns worldwide, especially in developing countries [3]. In developing countries with high nutrient demands, chronic patients like HIV/AIDS are of high risk due to consumption of low-quality, monotonous food which leads to micronutrient and macronutrient deficiencies [4].

HIV/AIDS and malnutrition are both highly prevalent in many parts of the world, especially in Sub-Saharan Africa. 
The effects are interrelated and exacerbate one another in a vicious cycle [5]. Both HIV and malnutrition can independently cause progressive damage to the immune system and increased susceptibility to infection, morbidity, and mortality through opportunistic infections, fever, diarrhea, loss of appetite, nutrient absorption, and weight loss. HIV speciin Accally affects nutritional status by increasing energy requirements, reducing food intake, and adversely affecting nutrient absorption and metabolism [6].

Nondiversified diet can have negative consequences on individuals' health, well-being, and development, mainly by reducing physical, social, cognitive, reproductive, and immunological capacities [2]. The level of dietary diversity and its determinant on HIV positive individuals will play a crucial role in improving quality of nutritional care and counseling provided by healthcare providers which in turn improves clients quality of life and physical and social capacity [7].

Dietary diversity problem in Ethiopia occurs at all times of the year. The number of relief dependent population has increased from time to time, which indicate that famine has become more prevalent than worse food diversity problems [8]. If adequate measures are not taken, the catastrophic nature of HIV will ground down the economic activities of countries because the global number of People Living with HIV (PLHIV) is seriously increasing [9]. Food diversity problem in Ethiopia derives directly from dependence on undiversified (monotonous) livelihoods style based on lowinput, low-output rain fed agriculture and awareness problem $[10,11]$.

Inadequate dietary intake to meet the increased metabolic demands associated with HIV infection is likely to affect nutritional status in PLHIV, further lowering their immunity and hastening disease progression hence increased morbidity and mortality. The Ministry of Health has taken remarkable steps in addressing nutrition among PLHIV by developing the national nutrition in HIV/AIDS guidelines. Dietary diversity among HIV positive adults (18 years) is influenced by different factors. So, the current study assessed those factors which are significant for dietary diversity. There is also limited research document in Ethiopia and no published study conducted on this topic in the study area; therefore, it is essential to assess the current magnitude of dietary diversity and associated factors among People Living with $\mathrm{HIV}$ receiving care and support in the study area. Hence this study will be conducted to identify the level of dietary diversity and associated factors among PLHIV attending antiretroviral therapy (ART) clinics of Motta administrative town ART sites.

\section{Methods}

2.1. Study Design and Setting. Facility based cross-sectional study was conducted in Motta administrative town, East Gojjam zone, the Amhara Regional State from April 15 to 30, 2009 E.C. It is located $370 \mathrm{Km}$, Northwest of Addis Ababa, and the capital city of Ethiopia and $120 \mathrm{~km}$ Southwest of Bahir Dar city, the capital of the Amhara National Regional State, respectively. The town had two ART sites. These were Motta Hospital and Motta Health Center. Motta Hospital started ART chronic care in 1998 E.C. and it served more than two thousands nearby woreda HIV patients. Motta Health Centre served about $355 \mathrm{HIV}$ patients [12, 13].

2.2. Participants. The source population was all HIV positive adults aged 18 years and above registered for chronic medical care in Motta administrative town ART sites and those patients who were currently on ART attending Motta administrative town ART clinic during the data collection period were included in the study, while those respondents who were too sick and unable to communicate were excluded.

2.3. Sample Size Determination and Technique. The required sample size was calculated using a formula for the determination of sample size for a single population proportion, considering $58.8 \%$ [9] as the proportion of low dietary diversity $(\mathrm{P})$ with $5 \%$ level of significance $(\alpha)$, at $95 \%$ level of confidence for two-tail test and a marginal error or level of precision $(d)=5 \%$. The sample size $(n)$ then was calculated as follows:

$$
\begin{aligned}
\mathrm{n} & =\frac{\left(\mathrm{Z}_{\alpha / 2}\right)^{2}[\mathrm{P}(\mathrm{P}-1)]}{(\mathrm{d})^{2}}=\frac{(1.96)^{2}[0.588(0.588-1)]}{(0.05)^{2}} \\
& =373
\end{aligned}
$$

The final sample by adding $10 \%$ nonresponse rate becomes 410.

Stratified sampling was used to select the required samples. First classify the health institutions stratified into two strata. Those were Hospital and Health Centre. Sampling frame was constructed by using the list from daily patient flow from both health institutions and proportionally allocated sample for each health institution and then simple systematic random sampling technique was used to select study units (participants) at every $\mathrm{K}^{\text {th }}\left(4^{\text {th }}\right)$ intervals ( $\mathrm{k}$ was sampling fraction, which was calculated as N/n=1433/329 $\approx 4$ for Motta Hospital and $\mathrm{N} / \mathrm{n}=355 / 81 \approx 4$ for Motta Health Centre). The numerators 1433 and 355 were the number of HIV positive clients currently on chronic care at Motta Hospital and Motta Health Center, respectively. The starting sample was selected by lottery method among the first four clients. The procedure was continued until the required sample size was obtained.

2.4. Data Collection Tools and Procedures. Structured questionnaire and standardized individual dietary diversity score tool [14] were used to assess dietary diversity of adult PLHIV. The questionnaire was first prepared in English by reviewing literatures and translated into Amharic version, which later on translated to the English version to check its consistency and comparability of the finding. Four data collectors (diploma clinical nurses) and one supervisor (health officer) were recruited for data collection process in Motta town administrative ART sites. A one-day training was given for data collectors and supervisors on the objectives of the study, data collection methods, how to fill the information in the structured questionnaire, and the ethical aspect of how to 
approach the patient. Supervisors had checked completeness and consistency of the collected data by reviewing each completed questionnaire daily and onsite supervision was carried out during data collection periods.

2.5. Data Quality Control. The questionnaire was designed and modified into local context from previous related literatures. It was first prepared in English and then translated into the local language Amharic and then retranslated back to English by an expert who was fluent in both languages to maintain its consistency. Training was given for data collectors and supervisor. Pretesting of the questionnaire was made on $5 \%$ of sample size in the Gindewoyin Health Center prior to the actual data collection process. There after adjustments and corrections were effected to the tools after review following the pretest. The data collection process was strictly followed day to day by the supervisor and principal investigator.

2.6. Data Processing and Analysis. Data were coded and entered into Epi-data version 3.1 and were exported to SPSS version 20.0 for analysis. The data that needs coding were first recoded before analysis. Descriptive statistics like frequency and cross-tabulation was computed. The bivariate logistic regression analysis was used to assess the association between dependent and independent variables. Each independent variable was entered in the bivariate logistic regression. Finally, variables, which show associations in the bivariable logistic regression at $\mathrm{P}$ value of less than 0.2 with $95 \% \mathrm{CI}$, were entered into multivariable logistic regression and were declared statistically significant at $\mathrm{P}$ value of less than 0.05 with at $95 \%$ CI.

2.7. Ethical Consideration. Ethical clearance was obtained from Debre Markos University, College of Health Sciences, Ethical Review Committee, and letter of permission was obtained from Motta town administrative ART sites. The purpose of the study was explained to respondents and verbal informed consent will be obtained from participants. Confidentiality of information was maintained by omitting any personal identifier from the questionnaires. The collected data were kept in the form of file in secure place where no one can access it except the investigator.

\section{Results}

3.1. Sociodemographic and Economic Characteristics. 410 study participants were included in the analysis with overall response rate of $100 \%$. The majority of the respondents, $150(36.6 \%)$, belonged to age group of 35-44 years with the mean age of $37.0( \pm 9.63)$ years. Majority, $359(87.6 \%)$, were Christian orthodox followers and 279 (68.0\%) of the respondents were females. All of the respondents (100\%) were Amhara and 192 (46.8\%) were married. Majority, 214 (52.2\%), of the respondents cannot read and write. Regarding to occupation, $125(30.5 \%)$ of respondents were daily labourer and $315(76.8 \%)$ of respondents' place of residence were urban (Table 1).

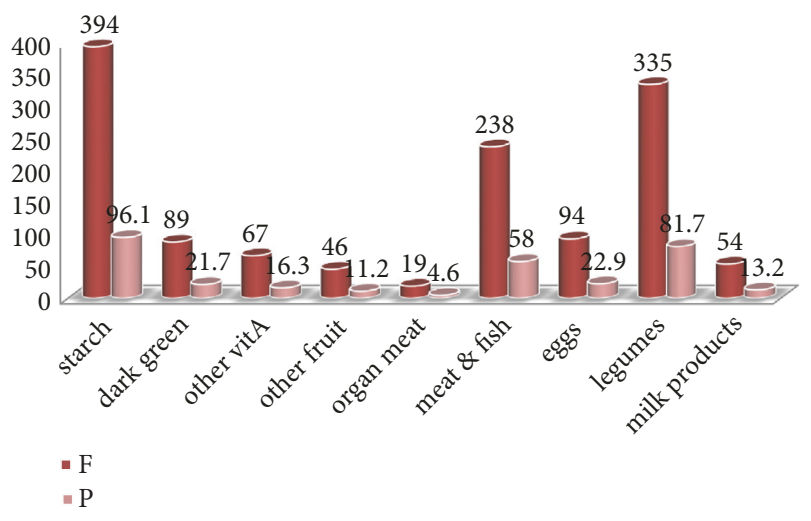

FIGURE 1: Twenty-four-hour food group consumption of adult HIV patients in Motta town public health facilities, April, 2017.

3.2. Behaviors Related Characteristics. Among the respondents, 140 (34.1\%) were counseled about drugs, 23 (5.6\%) about the illness, and 243 (59.3\%) about feedings. Most patients 391 (95.4\%) were counseled by healthcare providers whereas the others $17(2.2 \%)$ were by case managers. One hundred twenty-three (30\%) of the respondents were alcohol drunker and $11(2.7 \%)$ were chat chewer.

3.3. Health Related Characteristics. Regarding working status, $405(98.8 \%)$ of respondents could work their daily activities. One hundred seventy-three $(33.4 \%)$ of respondents were taking Cotrimoxazole prophylaxis of which $116(67.0$ $\% \%$ ) of them took for less than six years. $5.4 \%$ of the patients developed side effect related to ARV drugs while $0.7 \%$ and $3.9 \%$ developed side effect related to INH and CPT, respectively. 192 (46.8\%) of patients took AZT-3TCNVP based regimens and $5(1.2 \%)$ took second-line regimen. Among respondents 176 (42.9\%) of them took ART for less than three and half years (42 months). 405 (98.8\%) of respondents were currently under WHO clinical treatment stage one (T-1) and $230(68.3 \%)$ had baseline CD4 count of less than 350 cells $/ \mathrm{mm} 3$. Majority $376(91.7 \%)$ of the respondents had monthly follow-up and 392 (95.6\%) of the respondents had good adherence even if $2.9 \%$ of them lost due to their own reason (Table 2).

3.4. Level of Dietary Diversity. By considering the mean individual dietary diversity score, about $29.5 \%$ of HIV positive adults got diversified food. Starch staples (96.1\%) and legumes were food groups predominantly consumed by the patients with $96.1 \%$ and $81.7 \%$, respectively, whereas the least consumed food groups by the patients were organ meat (4.6\%) and milk products (13.2\%) (Figure 1).

3.5. Factors Associated with Level of Dietary Diversity. In multivariable logistic regression analysis, those patients who had cell phone means of communication were 2.13 times more likely to get diversified diet $(\mathrm{AOR}=2.13,95 \% \mathrm{CI}=1.16$, 3.60) compared to those who had not mobile cell phone. Those patients who had radio and television as means of source of information were 1.95 times more likely to get 
TABle 1: Sociodemographic characteristics of adult HIV positive patients in Motta administrative town ART sites, April, 2017.

\begin{tabular}{|c|c|c|c|}
\hline Sociodemographic variables & & Frequency $(\mathrm{N}=410)$ & Percent (\%) \\
\hline \multirow{2}{*}{ Sex } & Male & 131 & 32.0 \\
\hline & Female & 279 & 68.0 \\
\hline \multirow{4}{*}{ Age of the respondent } & $<25$ years & 27 & 6.6 \\
\hline & $25-34$ years & 139 & 33.9 \\
\hline & $35-44$ years & 150 & 36.6 \\
\hline & $\geq 45$ years & 94 & 22.9 \\
\hline \multirow{2}{*}{ Religion of the respondent } & Orthodox & 359 & 87.6 \\
\hline & Muslim & 51 & 12.4 \\
\hline \multirow{5}{*}{ Educational status } & Can't write and read & 214 & 52.2 \\
\hline & Write and read & 93 & 22.7 \\
\hline & Primary school & 38 & 9.3 \\
\hline & Secondary school & 54 & 13.2 \\
\hline & Certificate and above & 11 & 2.7 \\
\hline \multirow{4}{*}{ Marital status } & Single & 34 & 8.3 \\
\hline & Married & 192 & 46.8 \\
\hline & Divorced & 152 & 37.0 \\
\hline & Widowed & 32 & 7.8 \\
\hline \multirow{6}{*}{ Occupation } & Farmer & 109 & 26.6 \\
\hline & Government employed & 54 & 13.2 \\
\hline & Merchant & 90 & 22 \\
\hline & Daily laborer & 125 & 30.5 \\
\hline & Student & 9 & 2.2 \\
\hline & Others & 23 & 5.6 \\
\hline \multirow{2}{*}{ Residence } & Rural & 95 & 23.2 \\
\hline & Urban & 315 & 76.8 \\
\hline \multirow{2}{*}{ Family size } & $\leq 5$ people & 389 & 94.9 \\
\hline & $>5$ people & 21 & 5.1 \\
\hline \multirow{2}{*}{ Monthly income } & $<500$ birr & 105 & 25.6 \\
\hline & $\geq 500$ birr & 305 & 74.4 \\
\hline \multirow{3}{*}{ Source of food } & Farm/garden & 118 & 28.8 \\
\hline & Purchase & 279 & 68.0 \\
\hline & Relatives & 13 & 3.2 \\
\hline \multirow{2}{*}{ Farmland ownership } & Yes & 122 & 29.8 \\
\hline & No & 288 & 70.2 \\
\hline \multirow{2}{*}{ Livestock ownership } & Yes & 80 & 19.5 \\
\hline & No & 330 & 80.5 \\
\hline \multirow{2}{*}{ Dummy cultivating land } & Yes & 65 & 15.9 \\
\hline & No & 345 & 84.1 \\
\hline \multirow{2}{*}{ Milk in the house } & Yes & 28 & 6.8 \\
\hline & No & 382 & 93.2 \\
\hline \multirow{2}{*}{ Chicken and eggs in the house } & Yes & 63 & 15.4 \\
\hline & No & 347 & 84.6 \\
\hline \multirow{2}{*}{ Mobile phone } & Yes & 220 & 53.7 \\
\hline & No & 190 & 46.3 \\
\hline \multirow{2}{*}{ Exposure to media sources } & Yes & 104 & 25.4 \\
\hline & No & 306 & 74.6 \\
\hline
\end{tabular}


TABLE 2: Health related information of adult HIV patients in Motta administrative town, April, 2017.

\begin{tabular}{|c|c|c|c|}
\hline Health related variables & & Frequency & Percent (\%) \\
\hline \multirow{2}{*}{ Working status of the respondent } & Working & 405 & 98.8 \\
\hline & Other & 5 & 1.2 \\
\hline \multirow{2}{*}{ Taking Cotrimoxazole prophylaxis } & Yes & 137 & 33.4 \\
\hline & No & 273 & 66.6 \\
\hline \multirow{2}{*}{ Duration of Cotrimoxazole } & $\leq 5$ years & 116 & 67.0 \\
\hline & $>5$ years & 21 & 33.0 \\
\hline \multirow{2}{*}{ Side effect of Cotrimoxazole } & Yes & 16 & 3.9 \\
\hline & No & 121 & 29.5 \\
\hline \multirow{2}{*}{ INH preventive therapy } & Yes & 30 & 7.3 \\
\hline & No & 380 & 92.7 \\
\hline \multirow{2}{*}{ INH side effect } & Yes & 3 & 0.7 \\
\hline & No & 27 & 6.8 \\
\hline \multirow{5}{*}{ ART regimen } & AZT-3TC-NVP & 192 & 46.8 \\
\hline & AZT-3TC-EFV & 30 & 7.3 \\
\hline & TDF-3TC-NVP & 33 & 8.5 \\
\hline & TDF-3TC-EFV & 148 & 36.1 \\
\hline & Other/second line & 5 & 1.2 \\
\hline \multirow{3}{*}{ ART duration } & 6-18 months & 50 & 12.2 \\
\hline & 19-42 months & 126 & 30.7 \\
\hline & $\geq 43$ months & 234 & 57.1 \\
\hline \multirow{2}{*}{ Side effect of ART } & Yes & 22 & 5.4 \\
\hline & No & 388 & 94.6 \\
\hline \multirow{3}{*}{ WHO stage } & $\mathrm{T}-1$ & 405 & 98.8 \\
\hline & T-2 & 4 & 1 \\
\hline & WHO-1 & 1 & 0.2 \\
\hline \multirow{2}{*}{ Opportunity infection } & Yes & 42 & 10.2 \\
\hline & No & 368 & 89.8 \\
\hline \multirow{3}{*}{ Follow-up interval } & Monthly & 376 & 91.7 \\
\hline & Every 2 months & 33 & 33.8 \\
\hline & Others & 1 & 0.2 \\
\hline \multirow{2}{*}{ Supplementary feeding } & Yes & 57 & 13.9 \\
\hline & No & 353 & 86.1 \\
\hline \multirow[t]{4}{*}{ Baseline CD4 } & $<200$ cells $/ \mathrm{mm} 3$ & 149 & 36.3 \\
\hline & $200-349$ cells $/ \mathrm{mm} 3$ & 131 & 32.0 \\
\hline & $350-499$ cells $/ \mathrm{mm} 3$ & 70 & 17.1 \\
\hline & $\geq 500$ cells $/ \mathrm{mm} 3$ & 60 & 14.6 \\
\hline \multirow{4}{*}{ Current CD4 } & $<200$ cells $/ \mathrm{mm} 3$ & 38 & 9.3 \\
\hline & $200-349$ cells $/ \mathrm{mm} 3$ & 69 & 16.8 \\
\hline & $350-499$ cells $/ \mathrm{mm} 3$ & 97 & 23.7 \\
\hline & $\geq 500$ cells $/ \mathrm{mm} 3$ & 206 & 50.2 \\
\hline \multirow{3}{*}{ Adherence } & Good & 392 & 95.6 \\
\hline & Fair & 10 & 2.4 \\
\hline & Poor & 8 & 2.0 \\
\hline
\end{tabular}

diversified diet $(\mathrm{AOR}=1.95,95 \% \mathrm{CI}=1.22,3.11)$ compared to those who had not media source and patients who got nutritional counseling were 2.17 times more likely to get diversified diet $(\mathrm{AOR}=2.17,95 \% \mathrm{CI}=1.09,4.67)$ compared to counterparts (Table 3 ).

\section{Discussion}

This cross-sectional study was conducted to determine dietary diversity in adult HIV positive patients in Motta town public health institutions, North West Ethiopia. The 
TABLE 3: Multivariate and bivariate logistic regression output showing factors associated with dietary diversity in adult HIV patients in Motta town public health facilities, April, 2017.

\begin{tabular}{|c|c|c|c|c|c|c|}
\hline \multirow{2}{*}{ S. No. } & \multirow{2}{*}{ Variables } & & \multicolumn{2}{|c|}{ Diversified diet } & \multirow{2}{*}{ COR at $95 \% \mathrm{CI}$} & \multirow{2}{*}{ AOR at CI $95 \%$} \\
\hline & & & Yes & No & & \\
\hline \multirow{2}{*}{1} & \multirow{2}{*}{ Having media exposure } & Yes & 62 & 42 & $3.65(1.56,8.56)^{*}$ & $1.95(1.22,3.11)^{* * *}$ \\
\hline & & No & 227 & 79 & 1.00 & 1.00 \\
\hline \multirow{2}{*}{2} & \multirow{2}{*}{ INH preventive therapy } & Yes & 15 & 15 & $2.59(1.22,5.47)^{*}$ & $1.47(0.467,4.61)$ \\
\hline & & No & 274 & 106 & 1.00 & 1.00 \\
\hline \multirow{2}{*}{3} & \multirow{2}{*}{ Cotrimoxazole } & Yes & 81 & 35 & $2.59(0.72,9.37)^{*}$ & $2.42(0.65,9.06)$ \\
\hline & & No & 19 & 3 & 1.00 & 1.00 \\
\hline \multirow{2}{*}{4} & \multirow{2}{*}{ Availability of Mobile phone } & Yes & 138 & 8 & $2.30(1.47,3.59)^{*}$ & $2.13(1.16,3.60)^{* * *}$ \\
\hline & & No & 151 & 39 & 1.00 & 1.00 \\
\hline \multirow{2}{*}{5} & \multirow{2}{*}{ Food source } & Farming & 154 & 76 & $1.48(0.96,2.29)^{*}$ & $0.79(0.36,1.85)$ \\
\hline & & Other & 135 & 45 & 1.00 & 1.00 \\
\hline \multirow{2}{*}{6} & \multirow{2}{*}{ Nutritional counseling } & Yes & 117 & 113 & $2.77(0.97,4.46)^{*}$ & $2.17(1.09,4.67)^{* * *}$ \\
\hline & & No & 172 & 8 & 1.00 & 1.00 \\
\hline \multirow{2}{*}{7} & \multirow{2}{*}{ Marital status } & Married & 127 & 65 & $1.48(0.967,2.27)^{*}$ & $1.20(0.53,2.72)$ \\
\hline & & Not ever married & 162 & 56 & 1.00 & 1.00 \\
\hline
\end{tabular}

Significant at ${ }^{*}$ p value $<0.2$ and ${ }^{* * *}$ p value $<0.05$.

finding of this study revealed that $29.5 \%$ of HIV positive adults have got diversified diet before 24 hours preceding the survey. This was in line with the study conducted in Hossana town, Ethiopia (32.1\%) [15]. But it was lower than the study conducted in Metema Hospital (42.2\%) [9], Jimma (44.2\%) [16], Kenya (37.7\%) [17], Eastern Uganda (41\%) [18], and Butajira Hospital, Ethiopia (61.2\%) [19]. This difference may be due to variations of study periods, geographical location, seasonal variability, and other sociodemographic factors.

Starch staples and legumes were food groups, predominantly consumed by the participants during the 24-hour recall, $96.1 \%$ and $81.7 \%$, respectively, in Motta public health institutions. This finding is in line with the study conducted in Butajira, Metema Hospital, Nigeria $[3,19,20]$. On the other hand, organ meat, milk, and milk products were the least consumed food group during the study periods. This is in line with studies conducted at Butajira, Ethiopia, and Metema, Ethiopia. But in Metema in addition to milk, eggs were the least consumed food groups $[3,19]$. The reasons might be due to the difference of socioeconomic status, study area, and periods and agrological differences.

This study finding revealed that adult HIV patients who had media exposure were two times more likely to get good diversified diet compared to counterparts. This finding is in line with studies done in central Uganda and South Gondar $[15,20]$. The probable reason for this finding may be adult HIV patients who exposed to media sources might capture information about feeding from local media sources. Currently in Ethiopia there are local media that broadcast nutrition and health messages. On the other hand, this study also showed that those patients who had mobile cell phone were more than two times more likely to have got diversified diet as compared to those who had not mobile cell phone. This could be due to patients who had mobile access to close contact with the healthcare provider and could get counseling and it is important for defaulter tracing mechanism to trace those defaulted individuals.

Those adult HIV patients who got nutritional counseling were more likely to have diversified diet as compared to those who did not get. The probable reason for this finding might be that those adult HIV patients who got nutritional counseling had higher chance to get advice about feeding pattern.

The study also showed that taking alcohol and smoking cigarettes had no association with dietary diversity which is in line with a study done in Uganda [21]. A finding in Botswana showed that age, marital status, and educational status affects the dietary diversity of the individual [22]. Other studies in Filipino [23] and Jimma [16] showed that household income had positive correlation with dietary diversity of the individual. Occupational status, sex, raring small animals, and cultivated dummy vegetables in the garden had significant association with an individual dietary diversity in Jimma [16] and South Gondar [24]. But the above listed variables did not show any association with dietary diversity in this study. A study finding in Metema Hospital also revealed that employment status, duration of anti-retro-viral treatment, and Cotrimoxazole prophylaxis had strong association with level of dietary diversity of an individual which is also in contrast with this study [3]. This may be attributed to many factors such as differences in the study area, study period, and study design.

This study may have certain limitations like recall bias and social desirability bias. And also since this is cross-sectional study design, it does not show real association.

\section{Conclusion and Recommendations}

The finding of this study revealed that diversified diet is a significant nutritional problem among HIV positive adults in 
public health facilities in Motta town. Nutritional counseling, having radio/television for source of information access, and having mobile were the factors contributing for dietary diversity. Therefore healthcare provider should focus on nutritional counseling and encourage the patients to use cell phone and increase awareness about the importance of media exposure.

$\begin{array}{ll}\text { Abbreviations } \\ \text { 3TC: } & \text { Lamivudine } \\ \text { AIDS: } & \text { Acquired immune deficiency syndrome } \\ \text { AOR: } & \text { Adjusted odds ratio } \\ \text { ART: } & \text { Antiretroviral therapy } \\ \text { AZT: } & \text { Zidovudine } \\ \text { CD4: } & \text { Cluster of differentiation } 4 \\ \text { CI: } & \text { Confidence interval } \\ \text { DDS: } & \text { Dietary diversity score } \\ \text { EDHS: } & \text { Ethiopian Demographic and Health Survey } \\ \text { PLWHIV: } & \text { People Living with HIV AIDS } \\ \text { WHO: } & \text { World Health Organization. }\end{array}$

\section{Data Availability}

The datasets used and/or analyzed during the current study are available from the corresponding author. The data will not be shared in order to preserve participant anonymity.

\section{Ethical Approval}

Ethical clearance was obtained from Debre Markos University, College of Health Sciences, Ethical Review Committee.

\section{Consent}

Letter of permission was obtained from Motta town administrative ART sites. The purpose of the study was explained to respondents and verbal informed consent was obtained from participants. Confidentiality of information was maintained by omitting any personal identification from the questionnaires. The collected data was kept in the form of file in secure place where no one can access it except the investigator.

\section{Conflicts of Interest}

The authors have declared that no conflicts of interest exist.

\section{Authors' Contributions}

Addisu Tesfaw was responsible for conceptualization. Addisu Tesfaw, Habtamu Temesgen, and Dube Jara were responsible for formal analysis; development or design of methodology; entering data into computer software; supervision; writing original draft; writing review and editing. Habtamu Temesgen and Dube Jara were responsible for validation. All authors read and approved the final manuscript.

\section{Acknowledgments}

We thank Debre Markos University, College of Health Science, for providing ethical clearance, data collectors, supervisors, Motta woreda administration, and study participants for their willingness to participate in the study.

\section{Supplementary Materials}

The supplementary file contains the questionnaire. The questionnaire has five parts: Part 1: sociodemographic factors of the respondents; Part 2: socioeconomic related questions; Part 3: behaviour and information related questions; Part 4: health related/clinical questions; Part 5: dietary diversity score questionnaire and additionally firstly there is information sheet and consent form. (Supplementary Materials)

\section{References}

[1] R. Jayawardena, N. M. Byrne, M. J. Soares, P. Katulanda, B. Yadav, and A. P. Hills, "High dietary diversity is associated with obesity in Sri Lankan adults: an evaluation of three dietary scores," BMC Public Health, vol. 13, no. 1, article 314, 2013.

[2] S. Drimie, M. Faber, J. Vearey, and L. Nunez, "Dietary diversity of formal and informal residents in Johannesburg, South Africa," BMC Public Health, vol. 13, no. 1, 2013.

[3] T. W. Amare, E. Y. Melkie, K. B. Teresa, and K. Y. Melaku, "Factors associated with dietary diversity among HIV positive adults (= 18 years) attending ART clinic at Mettema hospital, Northwest Ethiopia: cross-sectional study," Journal of AIDS and Clinical Research, vol. 6, no. 8, 2015.

[4] N. Nsele, "The effect of seasonal food variety and dietary diversity on the nutritional status of a rural community in KZN," 2014.

[5] A. C. Onyango, M. K. Walingo, G. Mbagaya, and R. Kakai, "Assessing nutrient intake and nutrient status of HIV seropositive patients attending clinic at Chulaimbo sub-district Hospital, Kenya," Journal of Nutrition and Metabolism, vol. 2012, Article ID 306530, 6 pages, 2012.

[6] R. K. Sachdeva, A. Sharma, A. Wanchu, V. Dogra, S. Singh, and S. Varma, "Dietary adequacy of HIV infected individuals in north India - A cross-sectional analysis," Indian Journal of Medical Research, vol. 134, no. 12, pp. 967-971, 2011.

[7] N. Mpontshane, J. Van Den Broeck, M. Chhagan, K. K. A. Luabeya, A. Johnson, and M. L. Bennish, "HIV infection is associated with decreased dietary diversity in South African children," Journal of Nutrition, vol. 138, no. 9, pp. 1705-1711, 2008.

[8] S. Drimie, G. Tafesse, and B. Frayne, Renewal Ethiopia Background Paper: HIV/AIDS, Food and Nutrition Security, International Food Policy Research Institute, Washington, DC, USA, 2006.

[9] P. K. Drain, R. Kupka, F. Mugusi, and W. W. Fawzi, "Micronutrients in HIV-positive persons receiving highly active antiretroviral therapy," American Journal of Clinical Nutrition, vol. 85, no. 2, pp. 333-345, 2007.

[10] T. D. B. Belachew and T. Temame, "Food insecurity and associated factors among people living with HIV attending ART clinic in Fitche zonal Hospital, Ethiopia," Journal of Pharmacy and Alternative Medicine, vol. 8, no. 3, pp. 408-411, 2015. 
[11] T. Belachew, C. Hadley, D. Lindstrom, A. Gebremariam, C. Lachat, and P. Kolsteren, "Food insecurity, school absenteeism and educational attainment of adolescents in Jimma Zone Southwest Ethiopia: a longitudinal study," Nutrition Journal, vol. 10, no. 1, article 29, 2011.

[12] "Administrative Mt: Annual woreda base plan," Unpublished, 2016.

[13] "Hospital. M: Annual hospital based plan," Unpublished, 2016.

[14] G. Kennedy, T. Ballard, and M. C. Dop, Guidelines for Measuring Household and Individual Dietary Diversity, Food and Agriculture Organization of the United Nations, 2011.

[15] S. De Pee and R. D. Semba, "Role of nutrition in HIV infection: Review of evidence for more effective programming in resource-limited settings," Food and Nutrition Bulletin, vol. 31, no. 4, pp. S313-S344, 2010.

[16] B. T. Y. Tefera, "Dietary diversity among people 40 years and above in Jimma town, Southwest Ethiopia," Ethiopian Journal of Health Sciences, vol. 17, no. 3, pp. 115-119, 2014.

[17] M. L. Kemunto, "Dietary Diversity and Nutritional Status of Pregnant Women Aged 15-49 Years Attending Kapenguria District Hospital West Pokot County, Kenya," 2013.

[18] J. Bukusuba, J. K. Kikafunda, and R. G. Whitehead, "Food security status in households of people living with HIV/AIDS (PLWHA) in a Ugandan urban setting," British Journal of Nutrition, vol. 98, no. 1, pp. 211-217, 2007.

[19] D. Gedle, G. Mekuria, G. Kumera, T. Eshete, F. Feyera, and T. Ewunetu, "Food Insecurity and its associated factors among people living with HIV/AIDS receiving anti-retroviral therapy at butajira hospital, Southern Ethiopia," Nutrition \& Food Sciences, 2015.

[20] S. R. Ajani, "An assessment of dietary diversity in six Nigerian states," African Journal of Biomedical Research, vol. 13, no. 3, pp. 161-167, 2010.

[21] D. Carol, "Factors associated with dietary intake among hiv positive adults (18-65 years) at the mildmay center, Kampala, Uganda," 2004.

[22] S. D. Weiser, K. Leiter, D. R. Bangsberg et al., "Food insufficiency is associated with high-risk sexual behavior among women in Botswana and Swaziland," PLoS Medicine, vol. 4, no. 10, Article ID e260, pp. 1589-1598, 2007.

[23] G. L. Kennedy, M. R. Pedro, C. Seghieri, G. Nantel, and I. Brouwer, "Dietary diversity score is a useful indicator of micronutrient intake in non-breast-feeding Filipino children," Journal of Nutrition, vol. 137, no. 2, pp. 472-477, 2007.

[24] N. M. E. Girma, T. Degnet et al., "Dietary diversity and associated factors among rural households in South Gondar Zone, Northwest Ethiopia," Feed the Future, vol. 5, no. 2, article 9, 2015. 


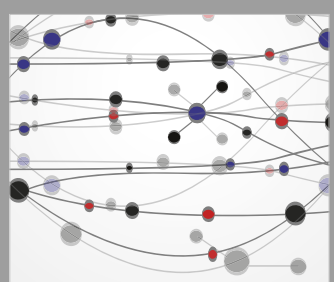

The Scientific World Journal
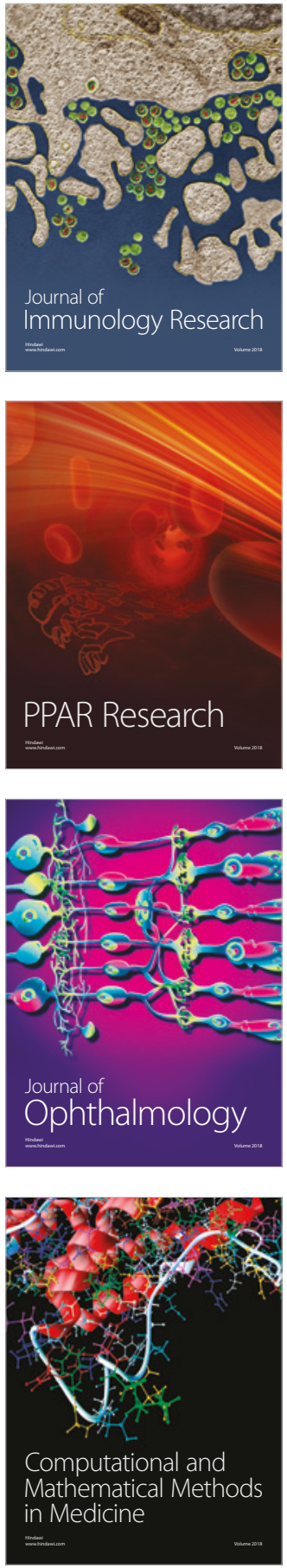

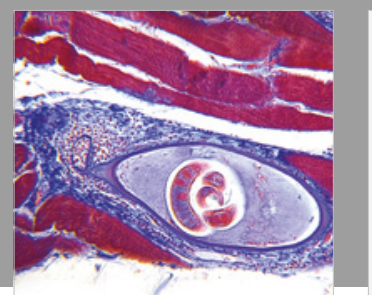

Gastroenterology Research and Practice

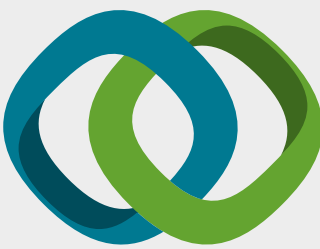

\section{Hindawi}

Submit your manuscripts at

www.hindawi.com
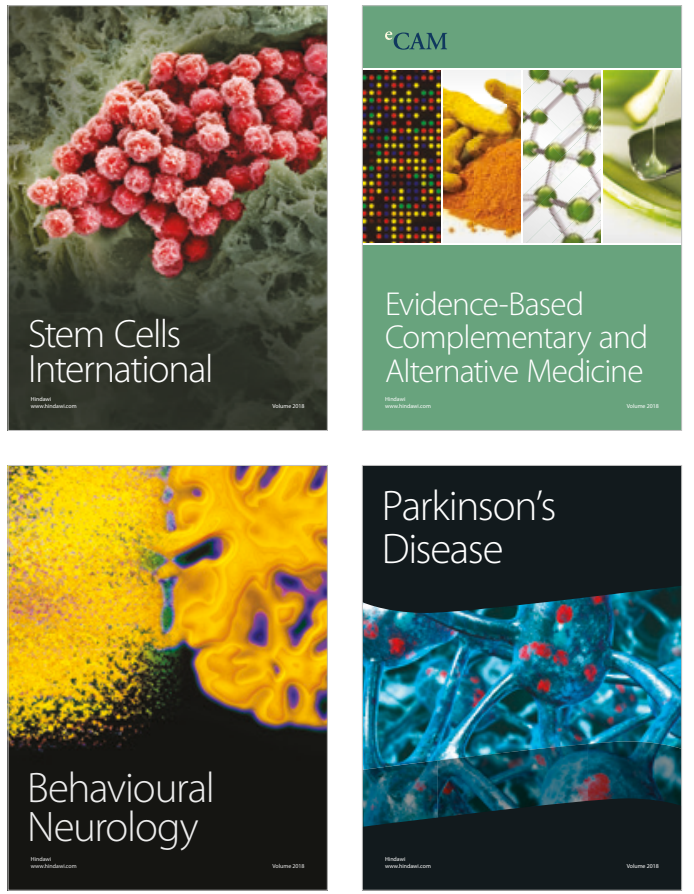

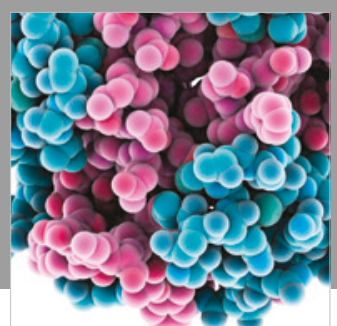

ournal of

Diabetes Research

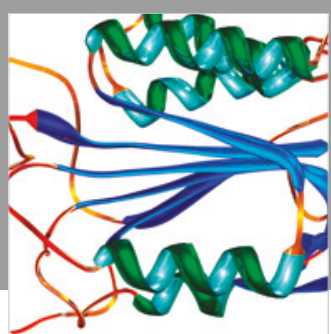

Disease Markers
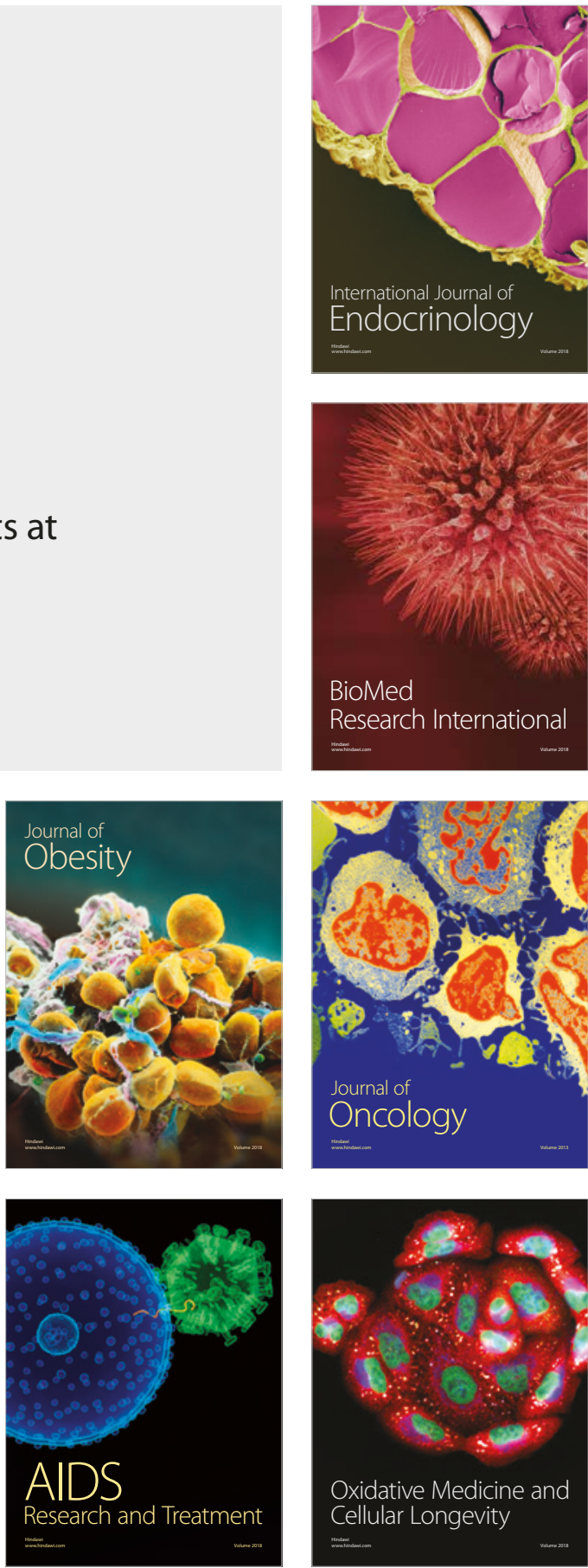